\title{
Implications of spatial distributions of snow mass and melt rate for snow-cover depletion: theoretical considerations
}

\author{
RiGHARD ESSERY, John POMEROY \\ Centre for Glaciology, Institute of Geography and Earth Sciences, University of Wales, Aberystwyth Sr23 3DB, Wales \\ E-mail: rie@aber.ac.uk
}

\begin{abstract}
Snow becomes patchy while melting, giving a heterogeneous surface with large contrasts in characteristics such as albedo. It is therefore necessary for surface schemes used in atmospheric and hydrological models to represent the influence of heterogeneities in snow cover on scales smaller than the model grid; this is typically done by introducing a snow-cover depletion (SCD) curve relating fractional snow cover to average depth. Here, ad hoc functional forms which have been used for this relationship are first compared with forms obtained for an assumed initial snow distribution undergoing homogeneous melt. The energy available for melt may be heterogeneous, however, and can be influenced by factors that also influence snow distribution, such as slope, aspect and vegetation cover. The modification of SCD curves by spatial variations in melt energy is investigated, and resulting curves are found to be similar to those which would be given by homogeneous melting of a snow cover with greater initial variance. This influence is increased by any negative correlation between snow depth and melt rate.
\end{abstract}

\section{INTRODUCTION}

Snow deposition and redistribution are influenced by topography and land cover, so snow covers have spatial variations in depth. The energy available to melt snow varies with small-scale advection of heat from snow-free patches or exposed vegetation and variations in radiation with slope and aspect, so snowmelt will also be spatially variable. For both reasons, snow covers generally become patchy when melting. This occurs on a wide range of length scales; indeed, snowpatch geometries and snow-depth distributions have been found to have fractal characteristics (Shook and others, 1993; Shook and Gray, 1996). Because several of the factors influencing the melt energy also influence snow redistribution, there may be some spatial association between patterns of melt and snow water equivalent (SWE). Faria and others (2000) found a negative correlation between SWE and melt rate for snow beneath mixed boreal-forest canopies and suggested that longwave radiation and horizontal advection of heat from tree trunks accelerated the melt of shallow snow near trunks. In a dense spruce stand, however, Pomeroy and others (2001) found a distribution of melt energy but no significant correlation with SWE measured along a transect with $1 \mathrm{~m}$ spacing. R. J. Harding (personal communication, 2002) found an opposite tendency at larger scales for melt measured on a $20 \mathrm{~m}$ grid crossing an Arctic hill slope: the melt rate was greatest for the deepest snow, possibly because of a reduction in albedo caused by dust blown onto a drift from a scoured upwind area. Pomeroy and others (2003) found a negative correlation on scales of hundreds of metres across a subarctic valley with a snowdrift on its north-facing slope. They noted that redistribution of snow by wind could lead to either positive or negative correlation on small catchment scales depending on the aspect of the slopes on which prevailing winds build drifts. Processes operating on different scales will give spatial associations changing with the scale on which snow distributions are considered. The characteristics of observed SWE and melt distributions are further discussed by Pomeroy and others (2004).

Because snow has a strong influence on land-surface characteristics such as albedo, hydrological models and land-surface schemes used in atmospheric models have to represent the influence of heterogeneity at scales smaller than the model grid. This is usually done by using the fraction of snow cover to calculate effective surface parameters or to weight separate flux calculations for snow-covered and snow-free areas. From the average SWE $\bar{S}$ over the entire area (snow-covered and snow-free), snow-cover fraction $f$ is obtained using a snow-cover depletion (SCD) curve. Functional forms assumed by models for these curves have included

$$
f=\frac{\bar{S}}{\bar{S}+a}
$$

used by BATS (biosphere-atmosphere transfer scheme; Yang and others, 1997), ISBA (interaction soil-biosphereatmosphere; Douville and others, 1995) and MOSES (Meteorological Office surface exchange scheme; Essery and others, 2001),

$$
f=1-\exp \left(-\frac{\bar{S}}{a}\right)
$$

used by GISS (Goddard Institute of Space Studies; Hansen and others, 1983) and UKMO (U.K. Meteorological Office; 
Essery, 1997), and

$$
f=\min \left(\frac{\bar{S}}{a}, 1\right)
$$

used by CLASS (Canadian land-surface scheme; Verseghy, 1991) and SiB (simple biosphere; Sellers and others, 1996); $a$ is a parameter with the same dimensions as $\bar{S}$ ( $\mathrm{mm}$ or $\mathrm{kg} \mathrm{m}^{-2}$ ) in each case. Gray and Landine (1987), Donald and others (1995) and Hamlin and others (1998) also used linear functions to fit observed snow-cover depletion and albedo decay. In an offline test of BATS, Yang and others (1997) found that the alternative function

$$
f=\tanh \left(\frac{\bar{S}}{a}\right)
$$

based on albedo measurements by Baker and others (1991), gave a better match to observed snow-cover fractions for short vegetation than Equation (1). Roesch and others (2001) also suggested this form for flat, non-forested regions and introduced modifications for gridboxes with forests and substantial subgrid topography.

Applying SCD curves such as Equations (1-4) in atmospheric models, the parameter $a$ is often taken to be proportional to the roughness length of the surface on the assumption that a greater snow depth is required to mask taller vegetation. Hydrological investigations have more often focused on the fraction of snow-free ground emerging as shallower snow melts out in a snow cover of variable depth. In this paper, a synthesis is attempted by comparing the functional forms in Equations (1-4) with results obtained by integrating over SWE distributions assuming homogeneous melting. This is then extended to the case of inhomogeneous melt which may or may not be associated with SWE.

\section{HOMOGENOUS MELT}

Because topography and vegetation have strong influences on the redistribution of snow, there can be large contrasts in the statistical characteristics of snow cover over complex landscapes. Stratified sampling techniques are often employed to estimate the total snow mass over an area (Steppuhn and Dyck, 1974; Woo 1998); snow surveys are performed within representative landscape units, and the results are averaged using fractional areas of the surface types within the area of interest. Pomeroy and others (1998) gave a table of coefficients of variation (standard deviation divided by average) in SWE obtained from a large number of surveys categorized by land use, vegetation and land form. Values range from $<0.05$ in forests to $>0.5$ on prairies. Liston (2003) suggested a classification scheme based on temperature, topography and vegetation to provide values for use in global models. Data on snow distributions from small and mesoscale surveys may not be appropriate for application to large-scale model grids, and further investigations are required.

Several studies (Donald and others, 1995; Shook 1995; Essery and others, 1999; Faria and others, 2000) have found that pre-melt distributions of SWE over reasonably homogeneous surfaces can be approximated by the log-normal distribution

$$
p(S)=\frac{1}{\sqrt{2 \pi} S \sigma_{y}} \exp \left[-\frac{(\ln S-\bar{y})^{2}}{2 \sigma_{y}^{2}}\right],
$$

where

and

$$
\bar{y}=\frac{1}{2} \ln \left(\frac{S_{0}^{2}}{1+C_{\mathrm{s}}^{2}}\right)
$$

$$
\sigma_{y}^{2}=\ln \left(1+C_{\mathrm{s}}^{2}\right)
$$

for pre-melt average SWE $S_{0}$ and coefficient of variation $C_{\mathrm{s}}$. Beta and gamma distributions have also been used to fit observed snow distributions (Kuchment and Gelfan, 1996; Brubaker and Menoes, 2001). The scales on which such unimodal distributions can be applied will depend on the complexity and length scales of the landscape under consideration.

Assuming a homogeneous melt amount $M$ for a snow cover with pre-melt distribution $p(S)$, the fractional area retaining snow cover is

$$
f=\int_{M}^{\infty} p(S) \mathrm{d} S
$$

and the average SWE remaining is

$$
\begin{aligned}
\bar{S} & =\int_{M}^{\infty}(S-M) p(S) \mathrm{d} S \\
& =\int_{M}^{\infty} S p(S) \mathrm{d} S-f M .
\end{aligned}
$$

For log-normal $p(S)$, Donald and others (1995) obtained the results

$$
f=\frac{1}{2} \operatorname{erfc}\left[\frac{\ln \left(M / S_{0}\right)+\sigma_{y}^{2} / 2}{\sqrt{2} \sigma_{y}}\right]
$$

and

$$
\frac{\bar{S}}{S_{0}}=\frac{1}{2} \operatorname{erfc}\left[\frac{\ln \left(M / S_{0}\right)-\sigma_{y}^{2} / 2}{\sqrt{2} \sigma_{y}}\right]-f \frac{M}{S_{0}},
$$

where erfc is the complementary error function. Shook (1995) and Luce and others (1999) used numerical integrations of Equations (8) and (9) to give equivalent results. Curves for $C_{\mathrm{s}}$ between 0.1 and 0.5 are plotted in Figure 1; greater values of $C_{\mathrm{s}}$ give flatter curves.

The SCD curves defined by Equations (10) and (11) have some inconvenient features for practical applications. A minor problem is that erfc is not provided as a standard intrinsic function by Fortran compilers. A library function could be used (e.g. NAG S15ADF), or Abramowitz and Stegun (1976) give

$$
\begin{aligned}
\operatorname{erfc}(x)= & \left(0.3480242 t-0.0958798 t^{2}\right. \\
& \left.+0.7478556 t^{3}\right) \mathrm{e}^{-x^{2}}+\epsilon
\end{aligned}
$$

where

$$
t=\frac{1}{1+0.47047 x}
$$

and the residual $|\epsilon|<2.5 \times 10^{-5}$ for $0 \leq x<\infty$; values for negative $x$ are obtained using $\operatorname{erfc}(-x)=2-\operatorname{erfc}(x)$. A more compact, though less accurate, approximation is 

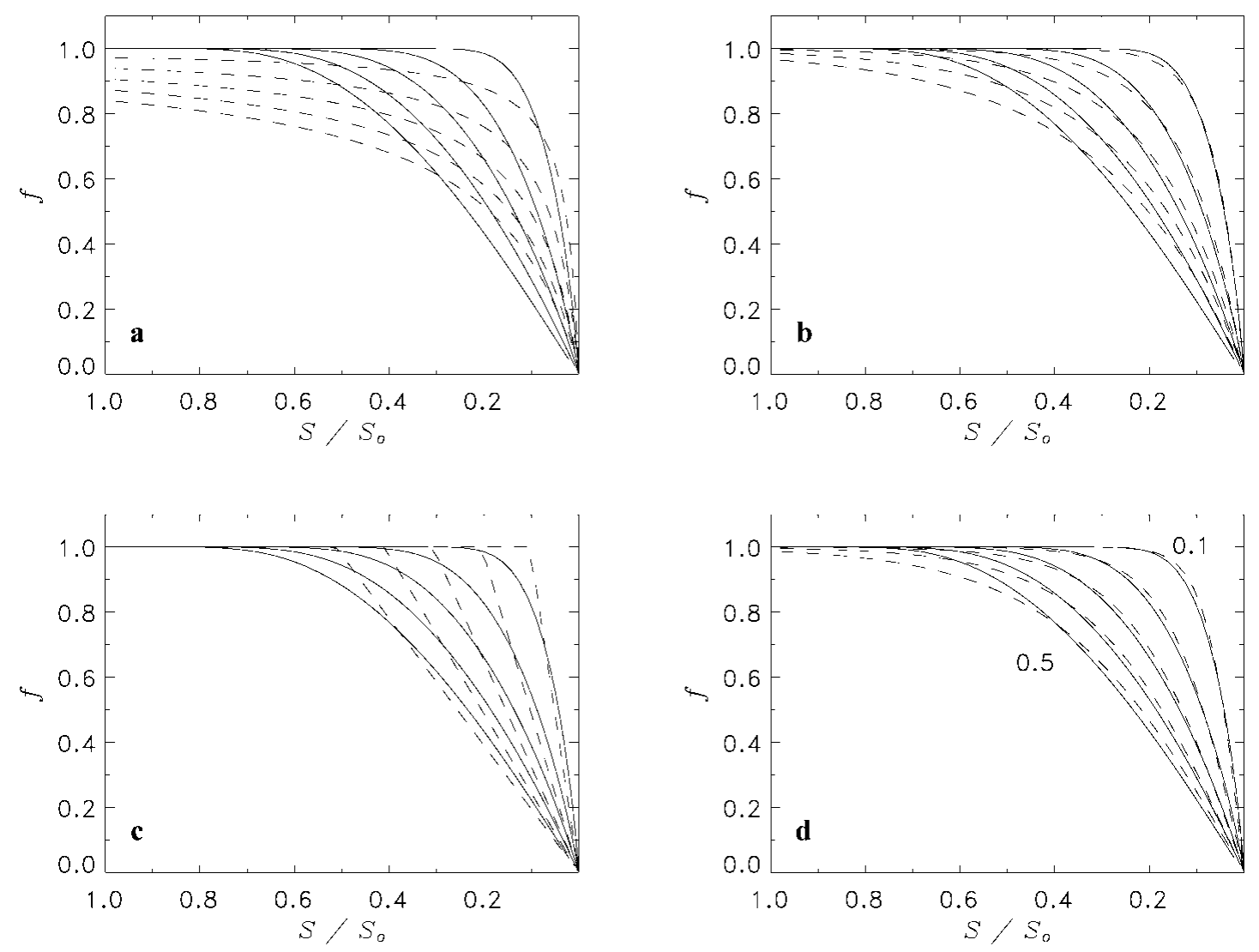

Fig. 1. ( $a-d)$ Log-normal $S C D$ curves with $C_{\mathrm{S}}=0.1, \ldots, 0.5$ (solid lines) compared with Equations (1-4) (dashed lines) in $(a-d)$, respectively. Lower curves are for larger values of $C_{\mathrm{s}}$.

given by

$$
\operatorname{erfc}(x)=\frac{2}{1+\exp (2.4 x)}+\epsilon
$$

with $|\epsilon|<0.02$ for all $x$.

A more serious problem with the log-normal SCD curve is that it is given in the parametric form $f(M)$ and $\bar{S}(M)$, whereas the SCD curves reviewed in the introduction all have the closed form $f(\bar{S})$. The parametric form can be used by storing the pre-melt $S_{0}$ and accumulated melt (Liston 2003), but to assess closed forms we attempt to adjust the parameters in Equations $(1-4)$ to fit log-normal SCD curves; results are shown by dashed lines in Figure 1, and the minimum rms errors obtained using each equation are shown in Figure 2. Because the shape of the log-normal SCD curve depends on $C_{\mathrm{s}}$ only, the parameter $a$ can be expected to be proportional to pre-melt standard deviation $\sigma_{0}$. This does not work for Equation (1); numerical

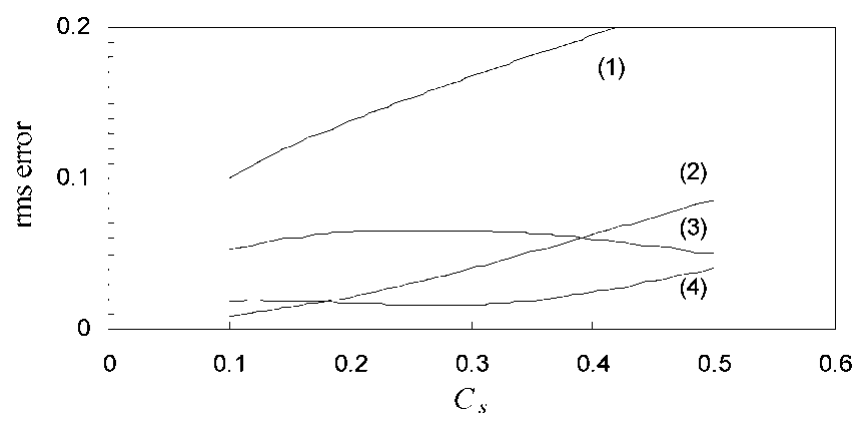

Fig. 2. Minimum rms errors obtained by fitting Equations (1-4) to log-normal SCD curves. minimization of the rms error gives

$$
f=\frac{\bar{S}}{\bar{S}+0.43 \sigma_{0}^{1.2}},
$$

but a close fit is not obtained. Equations (2) and (3), however, give reasonable fits for small $C_{\mathrm{s}}$ with

$$
f=1-\exp \left(-1.71 \frac{\bar{S}}{\sigma_{0}}\right)
$$

and

$$
f=\min \left(0.98 \frac{\bar{S}}{\sigma_{0}}, 1\right) .
$$

The best overall fit is given by Equation (4) with

$$
f=\tanh \left(1.26 \frac{\bar{S}}{\sigma_{0}}\right) \text {. }
$$

The common observations that snow depths have lognormal distributions and that SCD curves can be fitted by Equation (4) are therefore consistent. An extremely close fit can be obtained by taking $f$ as a cubic polynomial in $\bar{S}$, but estimates of the coefficients as functions of $C_{\mathrm{s}}$ are not robust.

\section{INHOMOGENEOUS MELT}

For inhomogeneous melt, Equations (8) and (9) are replaced by double integrals over the joint SWE and melt distributions. These integrals will generally be intractable, but SCD curves can still be obtained by numerical integration or simulation. Pomeroy and others (2001) simulated SCD curves by applying spatially varying melt rates obtained 

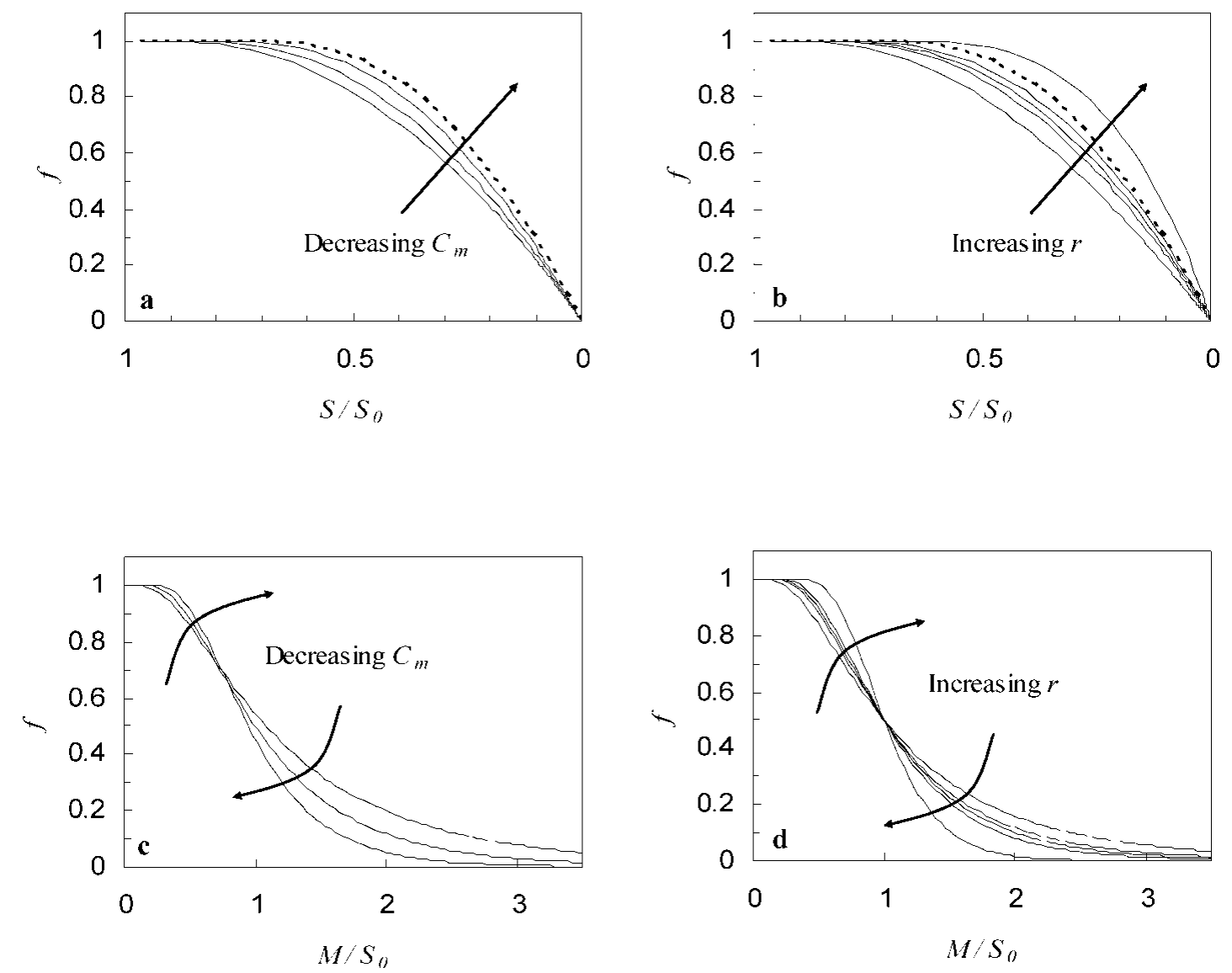

Fig. 3. ( $a, b)$ The influence of ( $a)$ melt variance $\left(C_{\mathrm{m}}=0.2,0.4,0.6\right.$ for $C_{\mathrm{s}}=0.4$ and $\left.r=-0.4\right)$ and (b) correlation $\left(r=-0.8,-0.4,0,0.4,0.8\right.$ for $C_{\mathrm{s}}=0.4$ and $\left.C_{\mathrm{m}}=0.4\right)$ on simulated SCD curves. Dashed lines show the homogeneous melt curve for $C_{\mathrm{s}}=0.4(c, d)$ The evolution of snow-cover fractions with cumulative applied melt.

from either a linear function of SWE or an uncorrelated distribution. Here, we consider correlated distributions of SWE and melt.

Correlated patterns of SWE and melt with log-normal distributions can be synthesized by first generating independent random fields $\epsilon$ and $\eta$ with zero means, unit variances and normal distributions. Correlated normal fields $x$ and $y$ are then obtained by the matrix multiplication

$$
\left(\begin{array}{l}
x \\
y
\end{array}\right)=\left(\begin{array}{ll}
a & b \\
b & c
\end{array}\right)\left(\begin{array}{l}
\epsilon \\
\eta
\end{array}\right) .
$$

The variances and correlation of $x$ and $y$ are

$$
\begin{gathered}
\sigma_{x}^{2}=a^{2}+b^{2}, \\
\sigma_{y}^{2}=b^{2}+c^{2}
\end{gathered}
$$

and

$$
r_{x y}=\frac{(a+c) b}{\sigma_{x} \sigma_{y}}
$$

from which

$$
b^{2}=\frac{\sigma_{x}^{2}+\sigma_{y}^{2}-2 \sigma_{x} \sigma_{y} \sqrt{1-r_{x y}^{4}}}{4+\left(\sigma_{x}^{2}-\sigma_{y}^{2}\right)^{2}\left(\sigma_{x} \sigma_{y} r_{x y}^{4}\right)^{-1}} .
$$

Taking the negative root of Equation (23) for $b$ gives negative correlation. Log-normal fields are given by the transformations

$$
S=\exp \left(x-\sigma_{x}^{2} / 2\right)
$$

and

$$
M=\exp \left(y-\sigma_{y}^{2} / 2\right) .
$$

To generate fields with coefficients of variation $C_{\mathrm{s}}$ and $C_{\mathrm{m}}$, the variances of $x$ and $y$ are set to

$$
\sigma_{x}^{2}=\ln \left(1+C_{\mathrm{s}}^{2}\right)
$$

and

$$
\sigma_{y}^{2}=\ln \left(1+C_{\mathrm{m}}^{2}\right)
$$

The influences of melt variance and correlation on simulated SCD curves are shown in Figure $3 \mathrm{a}$ and b. A melt distribution with coefficient of variation $C_{\mathrm{m}}$ applied without correlation $(r=0)$ to a SWE distribution with coefficient of variation $C_{\mathrm{s}}$ gives a SCD curve lying below the homogeneous melt curve. This tendency is increased by negative correlation because areas with shallow snow cover melt faster and become snow-free sooner. For sufficiently strong positive correlation, however, the SCD curve lies above the homogeneous melt curve because slower melt of shallow snow delays the appearance of snow-free patches. The influence of spatial variations in melt is similar to the influence of different coefficients of variation for snow covers undergoing homogeneous melt and so can be represented within the same framework for the cases shown.

Plotting snow-cover fractions from simulations with differing correlation against cumulative melt as in Figure 3c and $\mathrm{d}$, rather than average remaining SWE, gives curves that cross over between early $\left(M<S_{0}\right)$ and late $\left(M>S_{0}\right)$ times. A positive correlation between SWE and melt delays 
the initial appearance of snow-free ground, compared with negative correlation, because the melt rate of the shallowest snow is reduced. The increased rate of melting for the deepest snow, however, leads to an earlier completion of melt.

\section{GONGLUSIONS AND DISGUSSION}

Assuming a log-normal distribution of SWE and homogeneous melt over an area, a SCD curve relating fractional snow cover to average snow depth during melt can be obtained in a parametric form. Of several more convenient closed forms, a hyperbolic tangent function was found to give the closest fit to the log-normal form; this may explain previous success in fitting tanh functions to albedo and snow-cover measurements over flat sites with short vegetation (Yang and others, 1997; Kunkel and others, 1999). The assumption of a log-normal SWE distribution limits the scales on which simple relationships can be applied, but they may be extended by stratification of heterogeneous areas according to topography and vegetation cover.

The energy available for melting snow can have spatial variations that may be correlated with SWE because of topographic or vegetative influences on both accumulation and ablation of snow (Pomeroy and others, 2004). A random or negatively correlated melt rate gives a SCD curve lying below the homogeneous melt curve, whereas positive correlation can reduce or reverse the influence of variations in melt.

Monotonic melt gives a well-defined SCD curve, but this will not always be the case. An ephemeral snowpack may go through several cycles of accumulation and ablation over the winter, introducing hysteresis in the relationship between SWE and $f$. Instead of the diagnostic SCD curves currently used in models, prognostic schemes may be required to account for the deposition, redistribution and melt history of a snowpack. Moore and others (1999) and Liston (2003) have introduced simple prognostic schemes.

This paper has assumed that SWE distributions are approximately log-normal, as observed from small-scale surveys within homogeneous landscape units. Above some length scale determined by topography and vegetation distributions, this assumption may break down as landscape units are bridged. In analogy with the stratification used in snow surveying (Steppuhn and Dyck, 1974) or the tiling used in land-surface modelling (Essery and others, 2003), snow cover could then be represented by a sum of distributions. Changes in the relationship between SWE and melt rate with scale are discussed in a companion paper (Pomeroy and others, 2004).

\section{ACKNOWLEDGEMENTS}

This work was supported by UK Natural Environment Council grants NER/J/S/2001/00812 and NER/A/S/2001/ 01089.

\section{REFERENCES}

Abramowitz, M. and I. A. Stegun. 1976. Handbook of mathematical functions. Washington, DC, U.S. Department of Commerce.

Baker, D. G., R. H. Skaggs and D. L. Ruschy. 1991. Snow depth required to mask the underlying surface. F. Appl. Meteorol., 30(3), 387-392.

Brubaker, K. L. and M. Menoes. 2001. A technique to estimate snow depletion curves from time-series data using the Beta distribution. Proc. East. Snow Conf., 58th, 343-346. (Annual Meeting, 14-17 May 2001, Ottawa, Ontario, Canada.)
Donald, J. R., E. D. Soulis, N. Kouwen and A. Pietroniro. 1995. A land cover-based snow cover representation for distributed hydrologic models. Water Resour. Res., 31 (4), 995-1009.

Douville, H., J.-F. Royer and J.-F. Mahfouf. 1995. A new snow parameterization for the Météo-France climate model. Part 1. Validation in standalone experiments. Climate Dyn., 12(1), 21-35.

Essery, R. 1997. Seasonal snow cover and climate change in the Hadley Centre GCM. Ann. Glaciol., 25, 362-366.

Essery, R. L. H., M. J. Best, R. A. Betts, P. M. Cox and C. M. Taylor. 2003. Explicit representation of subgrid heterogeneity in a GCM land surface scheme. F. Hydrometeorol., 4(3), 530-543.

Essery, R. L. H., M. J. Best and P. M. Cox. 2001. MOSES 2.2 technical documentation. Bracknell, Meteorological Office. Hadley Centre. (Technical Note 30.$)$

Essery, R., L. Li and J. Pomeroy. 1999. A distributed model of blowing snow over complex terrain. Hydrol. Processes, 13, 2423-2438.

Faria, D. A., J.W. Pomeroy and R. L. H. Essery. 2000. Effect of covariance between ablation and snow water equivalent on depletion of snowcovered area in a forest. Hydrol. Processes, 14, 2683-2695.

Gray, D. M. and P. G. Landine. 1987. Albedo model for shallow Prairie snow covers. Can. 7. Earth Sci., 24(9), 1760-1768.

Hamlin, L., A. Pietroniro, T. D. Prowse, E.D. Soulis and N. Kouwen. 1998. Application of indexed snowmelt algorithms in a northern wetland regime. Hydrol. Processes, 12, 1641-1657.

Hansen, J. and 7 others. 1983. Efficient three-dimensional global models for climatic studies: models I and II. Mon. Weather Rev., 111(4), 609-662.

Kuchment, L. S. and A. N. Gelfan. 1996. The determination of the snowmelt rate and the meltwater outflow from a snowpack for modelling river runoff generation. 7. Hydrol., 179(1-4), 23-36.

Kunkel, K. E., S. Isard, S. E. Hollinger, B. Gleason and M. Belding. 1999. Spatial heterogeneity of albedo over a snow-covered agricultural landscape. 7. Geophys. Res., 104(D16), 19,551-19,557.

Liston, G.E. 2003. Modelling regional and global scale subgrid heterogeneous snow cover. 7. Climate, 17(6), 1381-1397.

Luce, C. H., D. G. Tarboton and K. R. Cooley. 1999. Sub-grid parameterization of snow distribution for an energy and mass balance snow cover model. Hydrol. Processes, 13, 1921-1933.

Moore, R. J., V. A. Bell, R. M. Austin and R. J. Harding. 1999. Methods for snowmelt forecasting in upland Britain. Hydrol. Earth System Sci., 3(2), 233-246.

Pomeroy, J., R. Essery and B. Toth. 2004. Implications of spatial distributions of snow mass and melt rate on snowcover depletion: theoretical considerations. Ann. Glaciol., 38 (see paper in this volume).

Pomeroy, J.W., S. Hanson and D. Faria. 2001. Small-scale variation in snowmelt energy in a boreal forest: an additional factor controlling depletion of snow cover? Proc. East. Snow Conf., 58th, 85-96. (Annual Meeting, 1417 May 2001, Ottawa, Ontario, Canada.)

Pomeroy, J.W., B. Toth, R. J. Granger, N. R. Hedstrom and R. L. H. Essery. 2003. Variation in surface energetics during snowmelt in complex terrain. 7. Hydrometeorol., 4(4), 702-719.

Pomeroy, J.W. and 6 others. 1998. An evaluation of snow accumulation and ablation processes for land surface modelling. Hydrol. Processes, 12, 23392367.

Roesch, A. H., M. Gilgen, M. Wild and A. Ohmura. 2001. A new snow cover fraction parametrization for the ECHAM4 GCM. Climate Dyn., $17(12), 933-945$.

Sellers, P.J. and 8 others. 1996. A revised land surface parameterization (SiB2) for atmospheric GCMS. 1. Model formulation. 7. Climate, 10(4), 676-705.

Shook, K. R. 1995. Simulation of the ablation of prairie snowcovers. (Ph.D. thesis, University of Saskatchewan.)

Shook, K. and D. M. Gray. 1996. Small-scale spatial structure of shallow snowcovers. Hydrol. Processes, 10, 1283-1292.

Shook, K., D. M. Gray and J.W. Pomeroy. 1993. Temporal variation in snowcover area during melt in prairie and alpine environments. Nord. Hydrol., 24(2-3), 183-198.

Steppuhn, H. and G. E. Dyck. 1974. Estimating true basin snowcover. In Santeford, H. S. and J. L. Smith, eds. Advanced concepts and techniques in the study of snow and ice resources. Washington, DC, National Academy of Sciences, 314-328.

Verseghy, D.L. 1991. CLASS - a Canadian land surface scheme for GCMs. I: Soil model. Int. f. Climatol., 11(1), 111-133.

Woo, M. K. 1998. Arctic snow cover information for hydrological investigations at various scales. Nord. Hydrol., 29(4-5), 245-266.

Yang, Z.-L., R. E. Dickinson, A. Robock and K.Y. Vinnikov. 1997. On validation of the snow sub-model of the biosphere-atmosphere transfer scheme with Russian snow cover and meteorological observational data. 7. Climate, $\mathbf{1 0}(2), 353-373$. 